\title{
The Absence of Large Ulcer Predicts Latent Cytomegalovirus Infection in Ulcerative Colitis with Positive Mucosal Viral Assay
}

\author{
Mika Omiya, Mitsunobu Matsushita, Toshihiro Tanaka, Seiji Kawamata and Kazuichi Okazaki
}

\begin{abstract}
Objective Although many studies have shown that cytomegalovirus (CMV) infection is an exacerbating factor in patients with ulcerative colitis (UC), there is no valid method to distinguish CMV infection requiring therapy from that disappearing without therapy. The aim of this study was to describe whether or not the endoscopic feature of a large ulcer predicts the necessity of antiviral therapy against CMV infection in active UC patients with positive mucosal viral assay.

Methods Active UC patients in whom CMV infection was detected by mucosal polymerase chain reaction (PCR) assay were enrolled in this prospective observational clinical study. Patients with a large ulcer (ulcerated group) were treated with antiviral and UC therapy. Patients without a large ulcer (non-ulcerated group) were treated with only UC therapy. We prospectively evaluated the clinical and endoscopic findings in all of the patients 2 months after starting this protocol, and observed their outcomes during one year.

Results In the ulcerated group $(\mathrm{n}=10), 3$ patients still had active disease at 2 months and underwent colectomy. Although the other 7 patients achieved remission at 2 months, 4 of the 7 patients had a flare-up, and the remaining 3 patients maintained remission. All of the patients in the non-ulcerated group $(n=10)$ attained remission without antiviral therapy at 2 months, and maintained remission.

Conclusion In active UC patients with positive CMV DNA by mucosal PCR assay, the absence of a large ulcer suggests latent CMV infection, and requires no antiviral therapy.
\end{abstract}

Key words: ulcerative colitis, cytomegalovirus infection, mucosal PCR assay, antiviral therapy

(Inter Med 49: 2277-2282, 2010)

(DOI: 10.2169/internalmedicine.49.3657)

\section{Introduction}

Cytomegalovirus (CMV) infection is very common among the general population, and occurs in over $60 \%$ of adults $(1,2)$. Primary CMV infection is generally asymptomatic or minimally symptomatic, and is followed by latent infection. CMV possesses many immunological evasive mechanisms to avoid detection and clearance, and to insure continued survival and replication (3-5). CMV is well known to be an important pathogen in immunocompromised patients, such as patients with acquired immunodeficiency syndrome (AIDS), and recipients of bone marrow or organ transplants. Patients with ulcerative colitis (UC) are usually immunosuppressed because of immunosuppressive medication and/or poor nutrition. Many studies have shown that CMV infection is an exacerbating factor in patients with UC and the prognosis of patients complicated by this infection is generally poor $(1,6-8)$.

Many techniques have been developed for detecting CMV infection, such as histopathology, serology, endoscopy, CMV antigenemia assay, and CMV DNA assay. CMV antigenemia assay has been widely used to diagnose and monitor CMV infection, but some studies suggest that antigenemia levels in UC patients are lower than those observed in transplant recipients with CMV infection $(9,10)$. CMV DNA assay is also used to diagnose and monitor CMV infection, but this method is not clear regarding the determination to start an- 
Table 1. Endoscopic Index of Blackstone

\begin{tabular}{lll}
\hline Activity & Grade & Appearance \\
\hline \multirow{2}{*}{ Quiescent } & 1 & Normal \\
& 2 & Distorted or absent mucosal vascular pattern \\
Mild & 3 & Granularity \\
& 4 & Continuous or focal erythma \\
Moderate & 5 & Friability (touch bleeding) \\
& 6 & Mucopurulent exduate (mucopus) \\
Severe & 7 & Single or multiple ulcers $(<5 \mathrm{~mm}) ;$ fewer than 10 per $10 \mathrm{~cm}$ segment \\
& 8 & Large ulcers ( $>5 \mathrm{~mm}) ;$ more than 10 per $10 \mathrm{~cm}$ segment \\
\hline
\end{tabular}

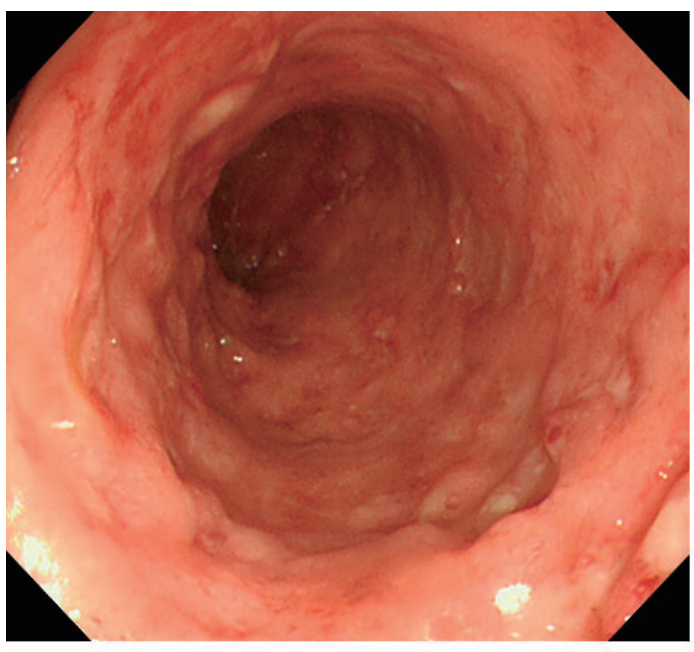

Ulcerated group

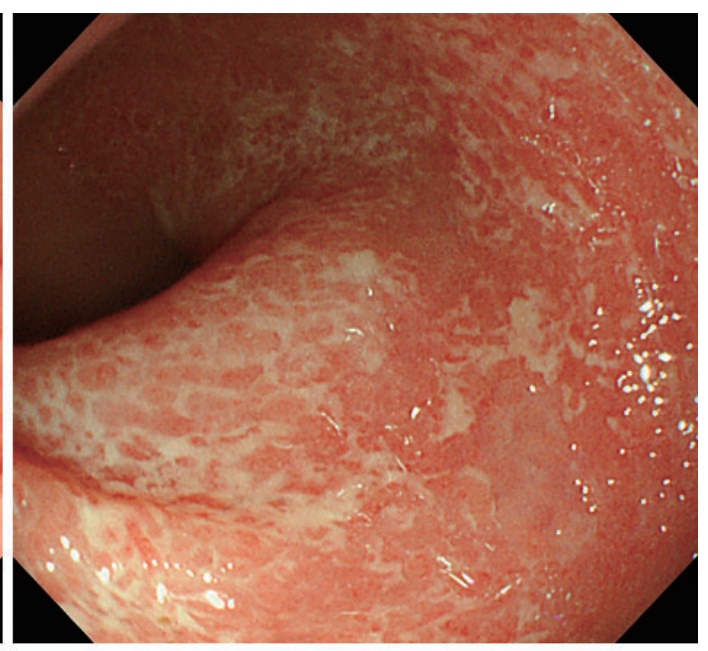

Non-ulcerated group

Figure 1. Endoscopic features of the ulcerated group (left) and non-ulcerated group (right).

tiviral therapy due to its high sensitivity (11). Recently, some studies have shown that a quantitative real-time polymerase chain reaction (PCR) assay with the use of colonic tissue is beneficial to estimate CMV infection (12), but this technique is not generally available. Whereas detection of CMV infection at an early stage and start of the appropriate treatment are important for UC patients, some studies have suggested that CMV is frequently reactivated in active UC patients, but disappears without antiviral therapy (9).

To date, there is no valid method to distinguish CMV infection requiring therapy from that disappearing without therapy, even with the use of combination of several modalities. The aim of this study was to describe whether the endoscopic feature of a large ulcer predicts the necessity of antiviral therapy against CMV infection in active UC patients with positive mucosal viral assay.

\section{Patients and Methods}

\section{Patients}

From January 2006 to January 2008, UC patients with moderate to severe activity (Seo's activity index) (13), in whom CMV were detected only by conventional PCR assay with the use of colonic tissue, but by neither CMV inclusion bodies in colonic mucosa (Hematoxylin and Eosin and CMV immunohistochemical staining) nor CMV antigenemia $(14,15)$, were included in this prospective study. The diagnosis of UC was made by clinical, endoscopic, and histological findings based on standard criteria $(16,17)$.

The protocol was approved by the ethical committee of our institution. We explained the method, its effectiveness, and the possibility of complications to the patients, and obtained their written informed consent before the study.

\section{Study design}

UC patients were divided into two groups, the ulcerated and non-ulcerated groups, based on endoscopic disease severity with the use of endoscopic index of Blackstone (Table 1) (18). The ulcerated group was defined by a Blackstone score of 7 or more, and included patients with a welldemarcated large ulcer. The non-ulcerated group was defined by a Blackstone score of 6 or less, and included patients without a large ulcer (Fig. 1). In the ulcerated group, pa- 
Table 2. Baseline Clinical Characteristics of Active UC Patients

\begin{tabular}{|c|c|c|c|}
\hline & Ulcerated group $(\mathrm{n}=10)$ & Non-ulcerated group $(\mathrm{n}=10)$ & $\mathrm{p}$ value \\
\hline Age (years) & $52.3 \pm 5.6$ & $44.2 \pm 4.2$ & 0.2585 \\
\hline Disease duration (years) & $6.3 \pm 2.1$ & $6.3 \pm 1.6$ & 1.0000 \\
\hline Extent of colorectal inflammation & & & 0.0821 \\
\hline Pan colitis & 10 & 6 & \\
\hline Left-sided colitis & 0 & 3 & \\
\hline Proctitis & 0 & 1 & \\
\hline Seo's activity index & $214 \pm 8.9$ & $170 \pm 6.4$ & 0.0008 \\
\hline Blackstone endoscopic score & $7.9 \pm 0.2$ & $6.0 \pm 0$ & $<0.0001$ \\
\hline Medication before entry & & & 0.6388 \\
\hline 5-ASA & 4 & 6 & \\
\hline $5-\mathrm{ASA}+\mathrm{PSL}$ & 4 & 2 & \\
\hline 5-ASA + PSL(local) & 2 & 2 & \\
\hline
\end{tabular}

Age, Disease duration, Seo's activity index, and Blackstone endoscopic index are expressed by mean (range).

5-ASA, 5-aminosalicylic acid; PSL, prednisolone.

tients were treated with antiviral therapy (ganciclovir at 5 $\mathrm{mg} / \mathrm{kg}$ twice a day for 2 weeks) and conventional UC therapy (prednisolone, azathioprine, 6-mercaptopurine, and/or apheresis). In the non-ulcerated group, patients were treated with only conventional UC therapy.

Clinical and endoscopic findings and mucosal PCR assay for CMV DNA were evaluated in all patients 2 months after starting this protocol, and we prospectively observed their outcomes throughout one year.

\section{Clinical activity}

Clinical activity of UC was assessed according to Seo's activity index (activity index $=60 \times$ blood stool $+13 \times$ bowel movements $+0.5 \times$ ESR- $4 \times$ HB-15x albumin +200$)$. Index values below 150 , values between 150 and 220 , and values above 220 nearly correspond to mild, moderate, and severe disease, respectively (13).

\section{Mucosal PCR assay of CMV DNA}

DNA for PCR assay, which is commercially available (SRL, Tokyo, Japan) in Japan, was extracted from the colonic tissue obtained by colonoscopic biopsy. The assay was performed with the DNA thermal cycler (Perkin/Elmer Cetus, Norwalk, CT). The oligonucleotide primers used for CMV-DNA amplification are constructed to detect the major immediate-early gene (MIE). The sequence of forward and reverse primers used in PCR are 5'-TTAGTGAACCGTCAGATCGC-3' and 5'-GCATGCATAAGAAGCCAAGG-3'. The PCR conditions were 40 cycles of $60 \mathrm{sec}$ at $94^{\circ} \mathrm{C}, 60 \mathrm{sec}$ at $58^{\circ} \mathrm{C}, 60 \mathrm{sec}$ at $72^{\circ} \mathrm{C}$. PCR products were subjected to electrophoresis and the amplicon bands were visualized by ultraviolet light. The presence of amplicon bands is considered as CMV DNA positive and the minimum detection level is

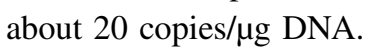

\section{Statistical analysis}

Continuous data were expressed as mean \pm SE. The Mann-Whitney $U$ test was used to analyze the variance on each factor between the groups. Categorical data were compared with the chi-square test. A p value $<0.05$ was considered statistically significant. These analyses were carried out with StatView-J5.0 software.

Results

For this study 20 patients (13 men and 7 women) were included. The ulcerated group consisted of 10 patients, and the non-ulcerated group of 10 patients. The baseline clinical characteristics of both groups are summarized in Table 2. Although Seo's activity index and Blackstone endoscopic score were significantly higher in the ulcerated group than those in the non-ulcerated group, there were no significant differences between the groups with regard to age, disease duration, extent of colorectal inflammation, and medication before entry. UC treatment after entry is shown in Table 3 $(\mathrm{p}=0.3107)$.

In the ulcerated group, three of the 10 patients $(30 \%)$ remained active at 2 months after, showing a Blackstone score of 6 or more and mean activity index of 214 (range 170260) (Fig. 2). These 3 patients underwent colectomy during the study period. The mean duration to operation after starting this protocol was 4 months (range 3-6 months), and none of them required emergency operation. The other seven patients $(70 \%)$ in the ulcerated group achieved remission at 2 months after, showing a Blackstone score of 3 or less and mean activity index of 114 (range 86-146). Four of these 7 patients had a flare-up during the study period, and the mean duration to flare-up after starting this protocol was 7.5 
Table 3. UC Treatment after Entry

\begin{tabular}{lcc}
\hline Treatment & $\begin{array}{c}\text { Ulcerated group } \\
(\mathrm{n}=10)\end{array}$ & $\begin{array}{c}\text { Non-ulcerated group } \\
(\mathrm{n}=10)\end{array}$ \\
\hline 5-ASA only & 2 & 2 \\
5-ASA + PSL (local) & 0 & 3 \\
5-ASA + PSL & 5 & 4 \\
5-ASA + AZA & 1 & 0 \\
5-ASA + PSL + GCAP & 0 & 1 \\
5-ASA + PSL + AZA + GCAP & 1 & 0 \\
5-ASA + 6-MP + GCAP & 1 & 0 \\
\hline
\end{tabular}

5-ASA, 5-aminosalicylic acid; PSL, prednisolone; AZA, azathioprine; 6-MP, 6-mercaptopurine; GCAP, granulocytapheresis.

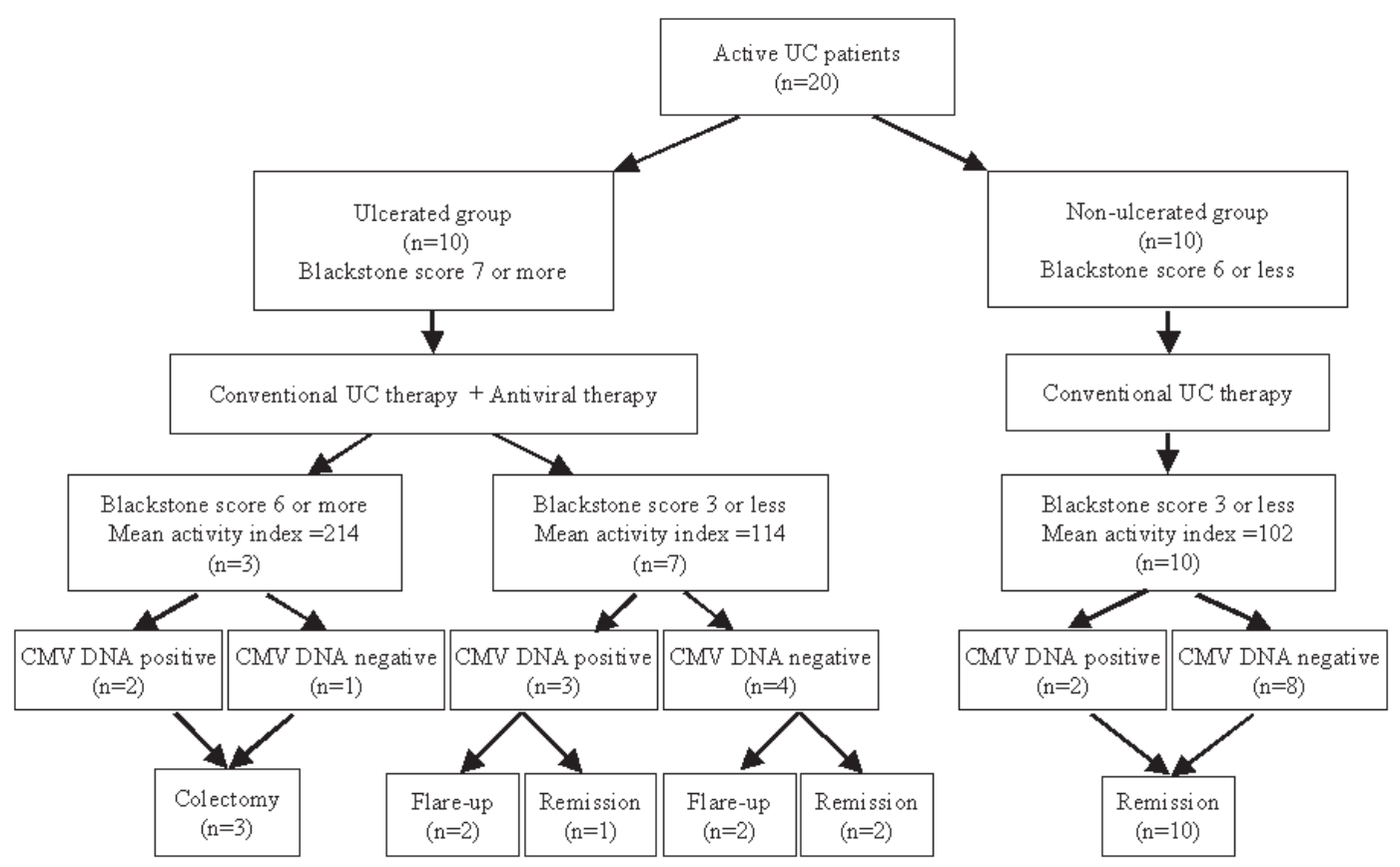

Figure 2. Outcomes of active UC patients with positive mucosal CMV DNA assay.

months (range 4-12 months). The remaining three patients maintained remission throughout the study period. In contrast, all 10 patients in the non-ulcerated group attained remission at 2 months after, showing a Blackstone score of 3 or less and mean activity index of 102 (range 81-132), and maintained remission throughout the study period.

We also evaluated CMV PCR assay of colonic tissue at 2 months after starting the protocol (Fig. 2). In the three patients who underwent colectomy, two were positive and the other patient was negative for the assay. In the other ulcerated group patients $(n=7)$, three patients were positive and the other 4 patients were negative for the assay. Two of the 3 patients with CMV DNA-positive and two of the 4 patients with CMV DNA-negative had a flare-up during the observation, and the other patient maintained remission. Al- though all 10 patients in the non-ulcerated group maintained remission, two patients were positive and the other 8 patients were negative for the assay.

\section{Discussion}

Whereas the principal reservoirs of CMV are fibroblasts, myeloid cells, and endothelial cells, the main infection organs of CMV disease are the eyes, lungs, and intestines $(7,15)$. CMV-infected individuals may show characteristic symptoms at different times, as well as may show coinfection at the same time (19), which indicates reactivation of the latent infection. Hommes et al. reported that colonic CMV disease in UC patients occurred only in seropositive patients, showing it to be a reactivation rather than a pri- 
mary infection (20). The current most widely accepted theory is as follows: there is a predominant increase and the activation of tissue macrophages and $\mathrm{T}$ cells in active UC patients with the subsequent release of cytokines to amplify the inflammatory response, and proinflammatory cytokines such as IFN- $\gamma$ and TNF- $\alpha$ induce the reactivation of CMV (21-23). Although histological diagnosis is considered the "gold standard" for diagnosing CMV infection in the gastrointestinal tract, $37.5 \%$ of patients with gastrointestinal CMV disease fail to reveal any inclusion (24).

CMV antigenemia assay is one of most widely used methods to detect CMV reactivation, and pre-emptive therapy with the use of this method has been shown to effectively prevent the occurrence of CMV disease in hematopoietic stem cell transplantation recipients (25). In contrast, antigenemia and plasma DNA levels in UC patients with gastrointestinal CMV disease are reported to be lower than those observed in transplant recipients $(9,10)$. Yoshino et al reported that CMV DNA was detected only in the inflamed colonic mucosa, but not in the noninflamed colonic mucosa in UC patients with CMV infection by the use of quantitative real-time PCR assay (12). We therefore considered that the CMV DNA assay with the use of colonic tissue is more reliable than blood tests for the detection of CMV reactivation in UC patients at an early stage. Because a quantitative real-time PCR assay is not generally available as noted above, we therefore applied a commercialized PCR assay with the use of colonic tissue in this study. However, it remains a serious problem that the detection level of the CMV DNA assay may not always indicate active CMV infection because it is also possible to detect a latent infection that is not associated with the exacerbation of UC.

Endoscopy is a useful modality for the diagnosis and assessment of UC patients. Endoscopic findings in CMV colitis include patchy erythema, exudates, micro erosions, diffusely edematous mucosa, multiple mucosal erosions, and well-demarcated or deep ulcers. There is no specific endoscopic findings in UC patients complicated CMV reactivation (26), thus it may be very difficult to distinguish active UC patients with CMV reactivation from exacerbation of UC itself. We often observe well-demarcated large ulcers in severe UC patients, which are also well known to be suggestive of CMV colonic infection.

In this study, active UC patients with a large ulcer (ulcerated group) were treated with antiviral therapy and conventional UC therapy. Because all 3 patients who did not achieve remission after 2 months of treatment underwent colectomy, we believe that endoscopic findings after antiviral therapy might be one of the predictors for colectomy. Active UC patients without a large ulcer (non-ulcerated group) were treated with only conventional UC therapy. Because all patients without a large ulcer attained remission and maintained remission throughout the observation, we considered that improvement of colonic symptoms by UC therapy caused resolution of CMV infection without antiviral therapy. On the other hand, we also evaluated CMV
DNA in colonic tissue after 2 months of treatment. Although 5 of the 17 patients who were remission after treatment were disclosed as CMV DNA positive, we believe that UC patients with CMV DNA positivity in remission have no viral morbidity. Although there is no consensus on how to manage active UC patients complicated by CMV reactivation, we believe that patients without a large ulcer can attain remission without antiviral therapy.

In conclusion, our study suggests that the absence of a large ulcer suggests latent CMV infection in active UC patients with a positive mucosal viral assay, and requires no antiviral therapy. Large controlled trials are needed to clarify the benefit of antiviral therapy for active UC patients with a deep ulcer based on endoscopic findings.

\section{Acknowledgement}

The authors thank Hiroshi Nakase, MD, (Department of Gastroenterology and Hepatology. Graduate School of Medicine, Kyoto University Hospital) for technical help. This study was supported by Health and Labour Science Research Grants from the Japanese Ministry of Health, Labour and Welfare, and Research on Measures for Intractable Disease (Inflammatory Bowel Disease).

This study was supported by Health and Labour Science Research Grants from the Japanese Ministry of Health, Labour and Welfare, and Research on Measures for Intractable Disease (Inflammatory Bowel Disease).

\section{References}

1. Papadakis KA, Tung JK, Binder SW, et al. Outcome of cytomegalovirus infections in patients with inflammatory bowel disease. Am J Gastroenterol 96: 2137-2142, 2001.

2. de Ory F, Ramírez R, García Comas L, León P, Sagües MJ, Sanz JC. Is there a change in cytomegalovirus seroepidemiology in Spain? Eur J Epidemiol 19: 85-89, 2004.

3. Froberg MK. Review: CMV escapes! Ann Clin Lab Sci 34: 123130, 2004.

4. Hengel H, Brune W, Koszinowski UH. Immune evasion by cytomegalovirus--survival strategies of a highly adapted opportunist. Trends Microbiol 6: 190-197, 1998.

5. Michelson S. Human cytomegalovirus escape from immune detection. Intervirology 42: 301-307, 1999.

6. Vega R, Bertrán X, Menacho M, et al. Cytomegalovirus infection in patients with inflammatory bowel disease. Am J Gastroenterol 94: 1053-1056, 1999.

7. Goodgame RW. Gastrointestinal cytomegalovirus disease. Ann Intern Med 119: 924-935, 1993.

8. Kishore J, Ghoshal U, Ghoshal UC, et al. Infection with cytomegalovirus in patients with inflammatory bowel disease: prevalence, clinical significance and outcome. J Med Microbiol 53: 1155-1160, 2004.

9. Matsuoka K, Iwao Y, Mori T, et al. Cytomegalovirus is frequently reactivated and disappears without antiviral agents in ulcerative colitis patients. Am J Gastroenterol 102: 331-337, 2007.

10. Kambham N, Vij R, Cartwright CA, Longacre T. Cytmegalovirus infection in steroid-refractory ulcerative colitis: a case-control study. Am J Surg Pathol 46: S59-S65, 2004.

11. Gerna G, Zipeto D, Parea M, et al. Monitoring of human cytomegalovirus infections and ganciclovir treatment in heart trans- 
plant recipients by determination of determination of viremia, antigenemia, and DNAemia. J Infect Dis 164: 488-498, 1991.

12. Yoshino $T$, Nakase $H$, Ueno $S$, et al. Usefulness of quantitative real-time PCR assay for early detection of cytomegalovirus infection in patients with ulcerative colitis refractory to immunosupressive therapies. Inflamm Bowel Dis 13: 1516-1521, 2007.

13. Lennard-Jones JE. Classification of inflammatory bowel disease. Scand J Gastroenterol 170: s2-s6, 1989.

14. Gower-Rousseau C, Salomez JL, Dupas JL, et al. Incidence of inflammatory bowel disease in northern France (1988-1990). Gut 35: 1433-1438, 1994.

15. Blackstone MO. Differentiation of ulcerative colitis from Crohn's colitis. In: Endoscopic Interpretation: Normal and Pathologic Appearance of the Gastrointestinal Tract. Blackstone MO, Ed. Raven Press, New York, 1984: 464-496.

16. Seo M, Okada M, Yao T, Ueki M, Arima S, Okumura M. An index of disease activity in patients with ulcerative colitis. Am J Gastroenterol 87: 971-976, 1992.

17. Eizuru Y, Minematsu T, Minamishima Y, et al. Rapid diagnosis of cytomegalovirus infections by direct immunoperoxidase staining with human monoclonal antibody against an immediate-early antigen. Microbiol Immunol 35: 1015-1022, 1991.

18. Rowshani AT, Bemelman FJ, van Leeuwen EM, van Lier RA, ten Berge IJ. Clinical and immunologic aspects of cytomegalovirus infection in solid organ transplant recipients. Transplantation 79: 381-386, 2005.

19. Tanaka K, Numazaki K, Tsutsumi H. Human cytomegalovirus ge- netic variability in strains isolated from Japanese children during 1983-2003. J Med Virol 76: 356-360, 2005.

20. Hommes DW, Sterringa G, van Deventer SJ, Tytgat GN, Weel J. The pathogenicity of cytomegalovirus in inflammatory bowel disease: a systematic review and evidence-based recommendations for future research. Inflamm Bowel Dis 10: 245-250, 2004.

21. Ardizzone S, Porro GB. Inflammatory bowel disease: new insights into pathogenesis and treatment. J Intern Med 252: 475-496, 2002.

22. Hahn G, Jores R, Mocarski ES. Cytomegalovirus remains latent in a common precursor of dendritic and myeloid cells. Proc Natl Acad Sci USA 95: 3937-3942, 1998.

23. Kandiel A, Lashner B. Cytomegalovirus colitis complicating inflammatory bowel disease. Am J Gastroenterol 101: 2857-2865, 2006.

24. Cotte L, Drouet E, Bissuel F, Denoyel GA, Trepo C. Diagnostic value of amplification of human cytomegalovirus DNA from gastrointestinal biopsies from human immunodeficiency virus-infected patients. J Clin Microbiol 31: 2066-2069, 1993.

25. Kanda $Y$, Mineishi S, Saito T, et al. Pre-emptive therapy against cytomegalovirus (CMV) disease guided by CMV antigenemia assay after allogeneic hematopoietic stem cell transplantation: a single-center experience in Japan. Bone Marrow Transplant 27: 437-444, 2001.

26. Sakamoto I, Shirai T, Kamide T, et al. Cytomegalovirus enterocolitis in an immunocompetent individual. J Clin Gastroenterol 34: 243-246, 2002.

(C) 2010 The Japanese Society of Internal Medicine http://www.naika.or.jp/imindex.html 